\title{
Primary Hyperoxalurias in Kuwaiti Arab Children: A 9-year Experience
}

\section{Amal Al-Eisa* and Wafa Al-Qabandi}

Department of Pediatrics, Faculty of Medicine, Kuwait University, 24923, Safat 13110, Kuwait

\section{Abstract}

Background: Primary hyperoxalurias $(\mathrm{PH})$ are a group of rare autosomal recessive metabolic disorders characterized by increased renal excretion of oxalate leading to nephrocalcinosis, chronic renal failure and later systemic oxalosis and multi-organ failure.

Methods: We conducted a retrospective review of all patients treated at the only pediatric nephrology center in Kuwait over 9 years. Patient's demographic and laboratory data and the disease outcome were reviewed.

Results: A total of 10 patients were included. Nine of them had PH type 1. Male:Female ratio was 2:1. Median age at diagnosis was 2 months. Patients below the age's of 1 and 5 years of age at diagnosis constituted $66 \%$ and $77 \%$ respectively. Positive family history of $\mathrm{PH}$ was reported in $66 \%$. First degree consanguinity was reported in $77 \%$ of families of affected patients and $44 \%$ of them had an affected sibling with PH1. Symptoms included: renal stones in 30\%, urinary tract infections in $22.5 \%$ and gross hematuria in $11 \%$. All patients had medullary nephrocalcinosis. Chronic kidney disease (CKD) was reported in $77 \%$ of patients at diagnosis, 5 of them were infants. End-stage renal disease (ESRD) was reported in $77 \%$, all were started on hemodialysis. Two patients had combined liver-kidney transplantation. Mortality rate was $44 \%$.

Conclusion: PH1 in Kuwaiti children has a severe form of the disease with an early onset and rapid progression to ESRD during infancy.

\section{Introduction}

Primary hyperoxalurias $(\mathrm{PH})$ are a group of rare autosomal recessive metabolic disorders characterized by increased excretion of oxalate and other metabolites caused by different enzymatic defect sat different steps of oxalate metabolism in the hepatocytes cytosol $[1,2]$. Subsequently calcium oxalate deposition in the kidneys and urinary tract takes place leading to nephrocalcinosis, stones formation and chronic kidney disease. In advanced disease when glomerular filtration rate declines, systemic oxalosis affects most vital body organs including heart, blood vessels, bones, joints and retina [3,4]. So far, 3 types of $\mathrm{PH}$ have been identified though more are believed to exist. PH type 1 is known to be the most severe type. It is caused by a deficiency of the enzyme alanineglyoxalate aminotransferase (AGT) associated with mutations in the AGXT gene encoded on chromosome $2[5,6,7]$. $\mathrm{PH} 2$ and $\mathrm{PH} 3$ are less common and less severe and caused by deficiency of the enzymes glyoxylate-reductase (GR) and 4-hydroxy-2-oxoglutarate aldolase 1 (HOGA1), respectively $[8,9]$. The phenotypic diversity of the disease in addition to its rarity leads to delayed diagnosis in many cases [10]. Epidemiology and clinical pattern of PH1 in the Middle East Region has not been reported previously. In this study we report our experience with PH1 in Kuwaiti Arab patients diagnosed in the only pediatric nephrology unit in Kuwait over a 9- year period.

\section{Patients and Methods}

A retrospective review of all patients with hyperoxalurias was conducted. This included all cases referred to the only pediatric nephrology center in Kuwait at Mubarak Al-Kabeer University hospital established in 1995. Demographic data of patients were analyzed including: age, gender, ethnic background, family history and consanguinity. The clinical pattern including presentation, management and prognosis were reviewed. Diagnosis of primary hyperoxaluria was suspected based on the clinical presentation of nephrocalcinosis, nephrolithiasis and/or chronic kidney disease. All patients had full blood workup including complete blood count, serum creatinine, blood urea, serum electrolytes, Sodium, Potassium, Chloride, bicarbonate level, Calcium, Magnesium, Phosphorus and alkaline phosphatase. Iron, transferrin and ferritin levels were monitored when anemia is present. Intact parathyroid hormone was checked on a monthly basis. Skeletal survey was done in some patients when indicated. All patients had full biochemical assay of plasma oxalate, 24- hour urine for oxalate, glyoxalic acid, glycolic acid (PH1)and glyceric acid (PH2) by radioimmunoassay (R.I.A) .Urinary oxalate levels were considered abnormal when values exceeded 50 $\mathrm{mg} / 1.73 \mathrm{M}^{2} / 24$ hours or $>0.46 \mathrm{mmol} /$ day as per lab values. Urinary glycolate excretion and L-glyceric acid excretion were considered abnormal when values exceeded $0.5 \mathrm{mmol}(45 \mathrm{mg}) / 1.73 \mathrm{M}^{2} / 24$ hours and $5 \mu \mathrm{mol} / \mathrm{L} /$ day, respectively. Liver biopsy and assay of the enzyme Alanine Glyoxylate Amino-Transferase (AGT) were performed in some patients who were sent to specialized centers outside Kuwait due to lack of such facilities locally. No genetic DNA studies were performed for mutation detection in any patient. Verbal consent to be included in the study was obtained from the care givers of all patients.

\section{Results}

A total of 10 patients below the age of 12 years were diagnosed with hyperoxaluria between 1995-2004. Primary hyperoxaluria was reported in 9 of them (90\%) while one patient had hyperoxaluria secondary to autoimmune enteropathy on total parenteral nutrition. All 9 patients with PH had type I disease. Male to female ratio was 2:1. Median age at diagnosis was 2 months (range 6 weeks- 12 years). The majority of patients (66\%) were infants at diagnosis, while $77 \%$ were less than 5 years of age. Mean serum creatinine level at diagnosis was $94 \mu \mathrm{mol} / \mathrm{l}$ (range $42-268 \mu \mathrm{mol} / \mathrm{l}$ ). Positive family history of PH1 or stone formation was reported in 6 patients $(66 \%)$, while 4 patients (44\%) had an affected sibling with PH1 including 2 families.

"Corresponding Author: Dr. Amal Al-Eisa, Department of Pediatrics, Faculty of Medicine, Kuwait University, 2492, Safat 13110, Kuwait; E-mail: amal@hsc.edu.kw

Citation: Al-Eisa A, Al-Qabandi W (2015) Primary Hyperoxalurias in Kuwaiti Arab Children: A 9-year Experience. Int J Pediatr Neonat Care 1: 106. doi: http://dx.doi. org/10.15344/2455-2364/2015/106

Copyright: (c) 2015 Al-Eisa et al. This is an open-access article distributed under the terms of the Creative Commons Attribution License, which permits unrestricted use, distribution, and reproduction in any medium, provided the original author and source are credited. 
Citation: Al-Eisa A, Al-Qabandi W (2015) Primary Hyperoxalurias in Kuwaiti Arab Children: A 9-year Experience. Int J Pediatr Neonat Care 1: 106. doi: http:// dx.doi.org/10.15344/ijpnc/2015/106

Page 2 of 3

The other 2 patients with late onset of PH1 (at 9 years \& 12years of age) had a strong family history of nephrolithiasis. Consanguinity with first-degree cousin marriage of parents of affected children was reported in 7 patients (77\%). Table 1 summarizes the presenting signs and symptoms of patients including nephrolithiasis, urinary tract infections, gross hematuria, nephrocalcinosis and chronic kidney disease. Out of a total of 7 patients developed chronic kidney disease. five were infants at time of the diagnosis (55\%). End- stage renal disease was reported in $77 \%$ of cases at a median age of 15 months (4 months -9.5 years) .Five of these patients were $<1$ year of age. Only 2 patients continued to maintain normal renal function after a mean followup period of 7 months (range 5-9 months). Table 2 summarizes the clinical data of the 9 patients with PH1. Medical management of all patients included the use of pyridoxine in a dose of $10-30 \mathrm{mg} / \mathrm{kg} / \mathrm{day}$ Bicitra, in a dose of $100-150 \mathrm{mg} / \mathrm{kg} /$ day and Magnesium Sulphate in some patients. Only one patient showed pyridoxine sensitivity with a reduction of urinary oxalate in a range of 30-50\%. Gastrostomy tubes were used in 5 patients for overnight feeds giving a total fluid intake of 2-3 liters per night. Hemodialysis was initiated in all 7 patients requiring renal replacement therapy. All had 3-4 hourly sessions 4-5 times per week.

\begin{tabular}{|l|l|l|}
\hline Clinical presentation & Patients(n=9) & $\%$ \\
\hline Urolithiasis & 3 & $33 \%$ \\
\hline Urinary tract infection & 2 & $22 \%$ \\
\hline Gross hematuria & 1 & $11 \%$ \\
\hline Nephrocalcinosis & 9 & $100 \%$ \\
\hline Chronic kidneydisease & 6 & $66 \%$ \\
\hline
\end{tabular}

Table 1: Clinical presentation of Primary Hyperoxaluria type 1 in Kuwaiti children.

\section{Discussion}

Primary hyperoxaluria type 1 is the most common hyperoxaluria affecting children. It accounts for 7-14\% of nephrocalcinosis [11] and $2-20 \%$ of urolithiasis in children [12-13]. In Europe, PH1 was reported to be the cause of CKD in one per 5-15 million children below the age of 16 years annually [14]. In USA, at least 30 new cases/ year of ESRD are due to PH1 [15]. Reports of PH1 in the Arab world are scarce with a reported prevalence of 5.5 per million children / year among Tunisian children [16]. In Kuwait, which is a small Arab country in the Middle East, PH1 was found to be the cause of $19 \%$ of urolithiasis in children [17]. It accounts for 3.5\% of CKD cases and $10.4 \%$ of ESRD cases in pediatric population in Kuwait $[18,19]$. The overall prevalence rate of $\mathrm{PH} 1$ in Kuwait was estimated to be7-10 / million child /year which are higher than rates reported in other parts of the world. This is expected in most metabolically inherited disease due to consanguinity and first degree-cousin marriages which are very popular in our geographic area.

Most of our patients (66\%) were infants at diagnosis and $77 \%$ were below the age of 5 years. More than half of the patients (55\%) had CKD and progressed to ESRD in infancy. This reflects the severity of PH1 in our region compared to the milder pattern of the disease reported in the Western World $[20,21]$. The high mortality rate of $44 \%$ in our study compared to $19 \%$ in France [20] also reflects the severity of the disease. This aggressive pattern of the disease most likely reflect the significant contribution of genetic factors in the disease manifestation. High consanguinity rate and first degree-cousin marriages are common cultural practices among Kuwaiti families particularly those with Bedouin (nomadic) roots. Most affected families came from regions in North of Kuwait where tribes of such background reside.

\begin{tabular}{|c|c|c|c|c|c|c|c|}
\hline No & Patients & Gender & $\begin{array}{l}\text { Age at Diagnosis } \\
\text { (months) }\end{array}$ & $\begin{array}{l}\text { S.Creatinine } \\
\text { at diagnosis }\end{array}$ & Age at ESRD & RRT & Outcome \\
\hline 1 & OS & $\mathrm{M}$ & 11 & 186 & 12 & HD & Death \\
\hline 2 & NN & $\mathrm{F}$ & 1 & 140 & 4 & HD & Death \\
\hline 3 & FS & $\mathrm{M}$ & 2 & 133 & 4 & HD & $\mathrm{L} / \mathrm{K}$ TX \\
\hline 4 & MN & $\mathrm{F}$ & 4 & 77 & 15 & HD & Death \\
\hline 5 & RS & M & 2 & 84 & 6 & HD & Death \\
\hline 6 & MA & M & 144 & 62 & - & - & - \\
\hline 7 & $\mathrm{AR}$ & $\mathrm{M}$ & 12 & 57 & 38 & $\mathrm{HD}$ & $\mathrm{L} / \mathrm{K} \mathrm{TX}$ \\
\hline 8 & AA & $\mathrm{F}$ & 18 & 48 & 118 & HD & L/K TX \\
\hline 9 & KM & M & 108 & 68 & - & - & - \\
\hline
\end{tabular}

Table 2: Clinical characteristics and outcome in 9 patients with Primary Hyperoxaluria (PH1).

-HD: hemodialysis, L/K TX: Combined liver kidney transplantation,ESRD:End-stage renal disease,RRT: Renal replacement therapy.

\section{Outcome}

At end of the study, two patients continued having normal renal function. Out of the 7 patients who were maintained on hemodialysis, 3 had combined liver- kidney transplant. Both had it in a specialized transplant centers outside Kuwait. Death was reported in 4 patients giving a mortality rate of $44 \%$. Three of the 4 patients died while receiving renal replacement therapy due to severe multi-organ failure secondary to systemic oxalosis, pulmonary hemorrhage and septic shock, respectively. The $4^{\text {th }}$ patient died in the early post-operative period following combined cadaveric liver-kidney transplantation. The patient who survived after a successful cadaveric combined liverkidney transplantation maintained normal renal function for 5 years but required a second living-related kidney graft afterwards.
Genetic and DNA studies showed the association of the most common mutation of $\mathrm{PH} 1$, which is p.Gly $170 \mathrm{Arg}$, with a better prognosis [22]. We believe our PH1 patients do have a different type of mutation which needs to be confirmed by extensive genetic testing of the affected patients as well as their family members. Despite Kuwait's pioneer role in Kidney transplantation in the Middle East, the lack of liver transplantation program, in addition to other cultural and religious factors, has inflicted a major financial burden on the health care system which is committed to provide the best and maximum care for $\mathrm{PH} 1$ patients?

\section{Conclusion}

PH1 is the commonest type of hyperoxalurias in pediatric 
Citation: Al-Eisa A, Al-Qabandi W (2015) Primary Hyperoxalurias in Kuwaiti Arab Children: A 9-year Experience. Int J Pediatr Neonat Care 1: 106. doi: http:// dx.doi.org/10.15344/ijpnc/2015/106

Page 3 of 3

population in Kuwait. The disease clearly has a more severe course compared to that in the western world evidenced by the early onset of CKD, rapid progression of the disease to ESRD in infancy and high mortality rate. This is more likely due to the strong genetic pooling caused by the high consanguinity rate which requires an extensive genetic work up.

\section{Competing Interest}

The authors declare that is no competing interests exist.

\section{Author Contributions}

Dr. Amal Al-Eisa declares that Dr. Wafa Al-Qabandi both the authors this paper contributed significantly to the design of the study and shared the care of the patients with the primary author. She also was involved in drafting and revising this paper.

\section{Acknowledgment}

We thank Mrs. Bena Rosy who helped in the secretarial work related to this manuscript.

\section{References}

1. Cochat P, Hulton SA, Acquaviva C, Danpure CJ, Daudon M, et al. (2012) Primary hyperoxaluria Type 1: indications for screening and guidance for diagnosis and treatment. Nephrol Dial Transplant 27: 1729-1736.

2. Harambat J, Fargue S, Bacchetta J, Acquaviva C, Cochat P (2011) Primary hyperoxaluria. Int J Nephrol 2011: 864580.

3. Watts RW (1994) Primary hyperoxaluria type 1. Q J Med 87: 593

4. Morgan SH, Purkiss P, Watts RW, Mansell MA (1987) Oxalate dynamics in chronic renal failure. Comparison with normal subjects and patients with primary hyperoxaluria. Nephron 46: 253-257.

5. Purdue PE, Lumb MJ, Fox M, Griffo G, Hamon-Benais C, et al. (1991) Characterization and chromosomal mapping of a genomic clone encoding human alanine:glyoxylate aminotransferase. Genomics 10: 34-42.

6. Purdue PE, Takada Y, Danpure CJ (1990) Identification of mutations associated with peroxisome-to-mitochondrion mistargeting of alanine/ glyoxylate aminotransferase in primary hyperoxaluria type 1 . J Cell Biol 111: 2341-2351.

7. von Schnakenburg C, Rumsby G (1997) Primary hyperoxaluria type 1: a cluster of new mutations in exon 7 of the AGXT gene. J Med Genet 34: 489-492.

8. Kemper MJ, Conrad S, Müller-Wiefel DE (1997) Primary hyperoxaluria type 2. Eur J Pediatr 156: 509-512.

9. Belostotsky R, Seboun E, Idelson GH, Milliner DS, Becker-Cohen R, et al. (2010) Mutations in DHDPSL are responsible for primary hyperoxaluria type III. Am J Hum Genet 87: 392-399.

10. Johnson SA, Hulton SA (2004) Primary hyperoxaluria. Saudi J Kidney Dis Transpl 15: 41-49.

11. Barrat TM, Danpure CJ (1994) Hyperoxaluira. In: Barrat TM and Avner ED Pediatric Nephrology, William and Wilkins, Baltimore, USA, 3rd edn, 557$572 p$.

12. Milliner DS (2005) The primary hyperoxalurias: an algorithm for diagnosis Am J Nephrol 25: 154-160.

13. Polinsky MS, Kaiser BA, Baluarte HJ (1987) Urolithiasis in childhood Pediatr Clin North Am 34: 683-710.

14. Latta K, Brodehl J (1990) Primary hyperoxaluria type I. Eur J Pediatr 149: 518-522

15. North American Pediatric Renal Trials and Collaborative Studies (NAPRTICS) Annual report (2010) Rockville, MD, USA: The EMMES Corporation.

Int J Pediatr Neonat Care

ISSN: $2455-2364$
16. Chemli J, Abdennabi H, Zorgati M, Abdelhak S, Nabli N, et al. (2007) [Primary hyperoxaluria in children in central Tunisia]. Tunis Med 85: 513518.

17. Al-Eisa AA, Al-Hunayyan A, Gupta R (2002) Pediatric urolithiasis in Kuwait Int Urol Nephrol 33: 3-6.

18. Al-Eisa A, Naseef M, Al-Hamad N, Pinto R, Al-Shimeri N, et al. (2005) Chronic renal failure in Kuwaiti children: an eight-year experience. Pediatr Nephrol 20: 1781-1785.

19. Al-Eisa AA, Samhan M, Naseef M (2004) End-stage renal disease in Kuwaiti children: an 8-year experience. Transplant Proc 36: 1788-1791.

20. Cochat P, Deloraine A, Rotily M, Olive F, Liponski I, et al. (1995) Epidemiology of primary hyperoxaluria type 1. Société de Néphrologie and the Société de Néphrologie Pédiatrique. Nephrol Dial Transplant 10 Suppl 8: 3-7.

21. Loirat C, Ehrich JH, Geerlings W, Jones EH, Landais P, et al. (1994) Report on management of renal failure in children in Europe, XXIII,1992.Nephrol Dial Transplant 9: S26-S40.

22. Harambat J, Fargue S, Acquaviva C, Gagnadoux MF, Janssen F, et al (2010) Genotype-phenotype correlation in primary hyperoxaluria type 1: the p.Gly170Arg AGXT mutation is associated with a better outcome. Kidney Int 77: 443-449. 